\title{
COMPUTER AIDED PROCESS PLANNING SYSTEM BASED ON MODULAR APPROACH
}

\author{
Vadim Skvortsov and Maria Skvortsova \\ Bauman Moscow State Technical University, Russia
}

\begin{abstract}
This article discusses the problem of the increase of machining process planning efficiency. The authors propose the way to design computer-aided process planning system based on modular approach to solve the problem. The first task was to change the subject of production and use specific elements of details, called a surface module. It is assumed that it is possible to decompose any detail into such elements. The second problem was to choose main parameters for checking the most efficiently technological operation. The result of this work is the automatized machining process system for processing parts for surface modules production.
\end{abstract}

\section{KEYWORDS}

CAPP, Modular Approach, Module of Surfaces, Features, Manufacturing, Expert System

\section{INTRODUCTION}

Nowadays process of manufacturing technological preparation takes about $50-70 \%$ of entire product production cycle length. This large time costs caused by a high level of labor consumption and low level of manufacturing processes planning automation. The first reason is a big diversity of means of technological support, parts and others units in the current engineering industry and duplication of work. The absence of a uniform classification, which makes it possible to uniquely identify and systematize work with these elements leads to a significant duplication of operations. Such overlap of work in the manufacturing is observed very often. Despite this fact a manufacturing preparation is still considered as a part of the whole system and is not studied deeply. The market lacks a solid solution, which would allow to optimize the preparation process, reduce time costs for this technological preparation stage several times and increase the automation level. This is also related primarily to a large amount of unstructured information stored in handbooks, supplier's databases, state and industry technical standards and other regulatory documents. Existing attempts to convert this information into a digital form don't lead to any notable results, and technologists still have to take their own decisions based on their personal experience. Furthermore, it is reasonable that the computer-aided process planning (CAPP) system should be multipurpose and not dependent on the manufacture specialization.

The preproduction engineering process can be divided into five stages. The overall level of automation now does not exceed 20\%. There is no doubt that the labor consumption and time of technological preparation of production can be reduced. One of modern approaches to solve the issue is based on principles of the modular technology. The basis of the technology is a representation of the product as a combination of surface modules (SM). The fundamental idea of this method resides in classification and possibility of decomposition of each part into a combination of surfaces. Such classification involves three different categories: basic, working and linking modules. This approach allows companies to create a set of hardware components for process steps, processing methods, equipment and tools at the module level and combine these elements to develop technological operations and processes. The modular machining operations integrate the advantages of a individual, typical and group technology considering all the features of a particular product as well as a single process [3]. The idea of typification is implemented at the level of manufacturing modules and combining products in groups by common modules, as in the group technology. 
The computer-aided process planning (CAPP) system is a link between computer-aided design (CAD - Computer-Aided Design) and compilation of the code for machines with CNC (CAM - Computer-Aided Manufacturing). In this software we should choose the most suitable machine tools, cutting conditions and other necessary information for technological processes and operations. Decisions made on this step have a great impact on the cost, quality and efficiency of a detail processing. Most of the work nowadays has not been automated yet and is performed manually by an engineer. For instance, technological analysis of a detail and defining of the possibility of processing the details on the base of parameters like detail geometry, dimensions, tolerances, and etc.

The idea of creation of a software for automatic development of technological processes and production planning has been discussed for a long time. However, as it was mentioned above, the solution of this problem is connected with some difficulties. One of them is a large variety of details. There is no possibility to create a database for all details due to their unlimited amount. The obvious way out is to go to the level of the features, which are clearly structured, limited and do not change over time. The result was a large amount of data that must be taken into account when developing the technological process. To handle and analysis all conditions, the authors used the basic principles of artificial intelligence and expert systems. This was one of the major problems that did not allow implementing the modular approach. Time of development of technological processes for the manufacture of parts can be reduced from several months to several hours and minutes, there will be the opportunity to create an enterprise knowledge base.

\section{TECHNOLOGY DESCRIPTION}

\subsection{CAPP System Development Approaches}

It's important to note that there are different approaches to technological process design method. In particular, there are significant differences between Russian and foreign standards for document processing. In this country these standards are defined in the corresponding GOST - at the federal level and OST - at the enterprise level. The input parameters are information about the detail, production volume, available equipment in the enterprise. There are three ways to obtain the initial data: DBF - Design by feature method, IFR - Interactive design feature recognition, AFR - Automated design feature recognition.

Based on these data, the matrix with information about items parameters is formed. Then a library of materials with known data on the hardness and brittleness of materials is loaded. The next stage is the formation of operations, cutting conditions, selection of machines and machine tools for operations. In order to determine the most effective combinations, the authors developed an expert system with predefined rules.

\subsection{Decomposition of Details into Elements}

A great variety of details does not allow to create a good and stable classification. We may see different ways to classify details and their surfaces, and most of them depend on time. It means they are changing and improved over time. While looking through surface elements, a great number of possibilities to combine them can be seen. It is important to note some approaches to automation of works with such surfaces:

- $\quad$ BMSTU professor A. Kondakov works on the hybrid CAPP for constructions (CAD) and processes (CAM) which will be able to reduce the duration of the technological preparation of details production. The essence of the study is in identifying the links between design and technological solutions and in combining these steps. The subject of production is so-called "T-complex" - a complex of surfaces, united by common shaping technology.

- Professor Y. Bochkarev carries out research on the creation of an automated system for multi nomenclature processes planning, the main principles of which are the complete formalization of design procedures, parallel technological processes design for all parts planned for processing. According to this method processing of individual surfaces is going to be parallel. 
- Professor O. Novikov carries out scientific research of a complex automation system of the TP design. The system is based on a formalization of parts description by building the structural models of elementary, complex, aggregated groups of surfaces.

Among the international scientists and developers, the most advanced works are from countries such as China and the United States. More than 30000 papers, describing various approaches to a possible solution to the problem has been published there in 2014-2017. But none of them makes it possible to exclude human involvement in the technological process design.

One of the main reasons is an unlimited number of design and technological elements. This problem can be solved by using modular technology in which there are a limited number of combinations of such surfaces and the structure is defined at the upper level: based, working and linking.

The modular approach to manufacturing preproduction was developed by Institute of Mechanical Engineering of the Russian Academy of Sciences. Currently, the work is performed in cooperation with the researchers from the Moscow State Technical University named after N.E. Bauman and Moscow State Technical University "Stankin". An example of decomposition of a detail is shown in Figure 1.

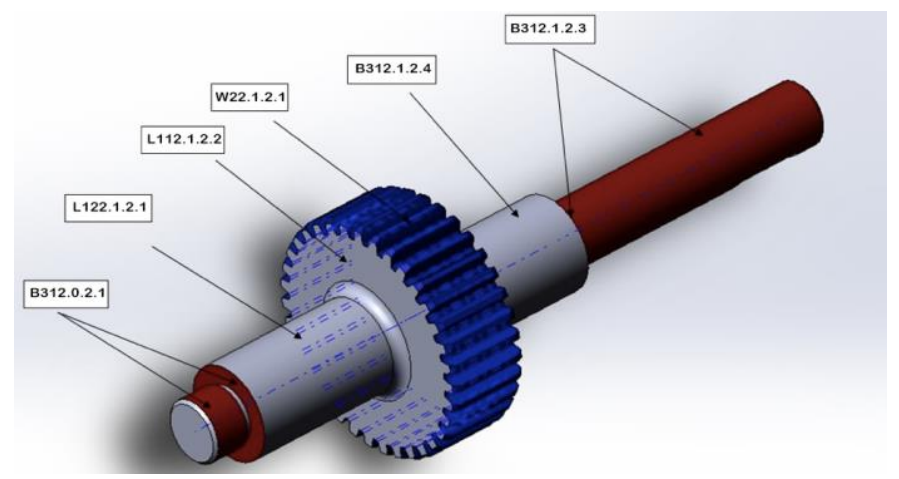

Figure 1. Three-dimensional model of the pinion shaft decomposed according to modular approach

Choosing module of surfaces as a basic element of the detail, caused by that:

- MSs are "elementary particles" of which any detail consists;

- MS does not depend on the purpose and construction of part;

- MS has a limited variety.

\section{CAPP SYSTEM BASED ON MODULAR APPROACH}

During the manufacturing operations planning at the unit level, we use module of surfaces as the subject of production, instead of a detail. In this case we need to decompose detail into many elements for the development of technological operation. Each element is assigned to its processing technology. To identify this term the following expression is used: modular processing technology (MPT). For the automation of selection of MPT, the engineer is proposed to use developed expert system based on modular technology. The expert system allows to design a modular process by choosing the most suitable MPT based on several criteria. This approach allows to significantly reduce the technological process design stage. 


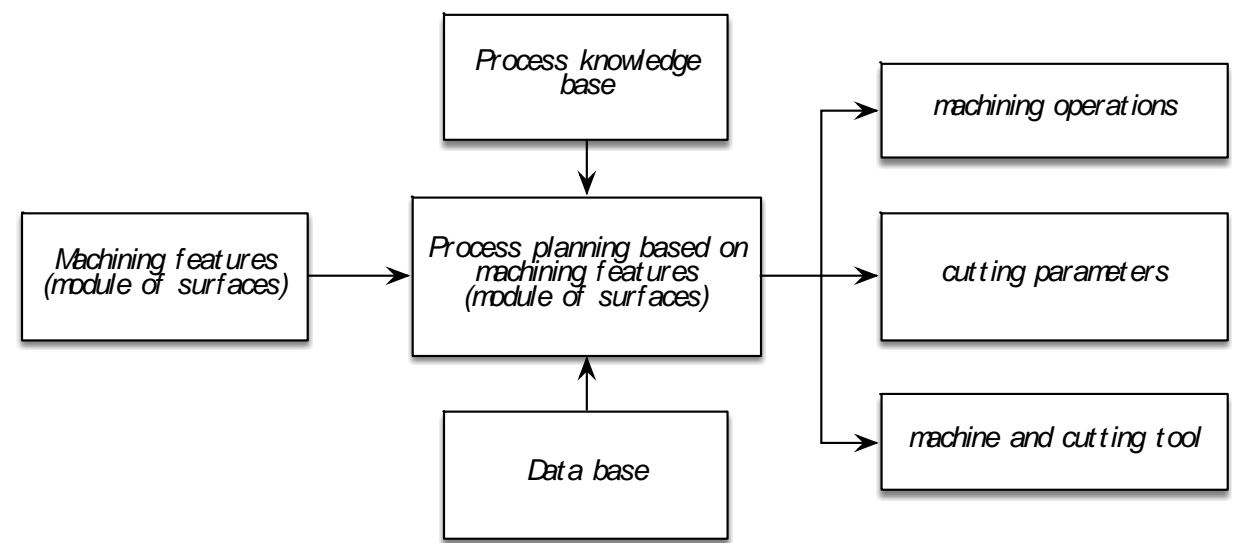

Figure 2. Scheme of the expert system

The general algorithm of the expert system is shown in Figure 2. In the first step, we need to get information about the details and define surface modules according to the developed classifier. In the case of an interactive input, technologist works with the CAPP system interface and enters data via the keyboard and computer mouse. Sometimes data can be entered incorrectly. For instances, it may be a result of human error. In order to solve the problem necessary checks have been added to the system. Also, the technologist must be well-versed in the modular technology and be able to decompose a detail into elements properly. Unfortunately, it's hard to imagine, because you need to manually process a large amount of information and additional training is needed. For the process acceleration the program interface has been simplified and divided into several steps. The interface for choosing the surface module is shown in Figure 3.

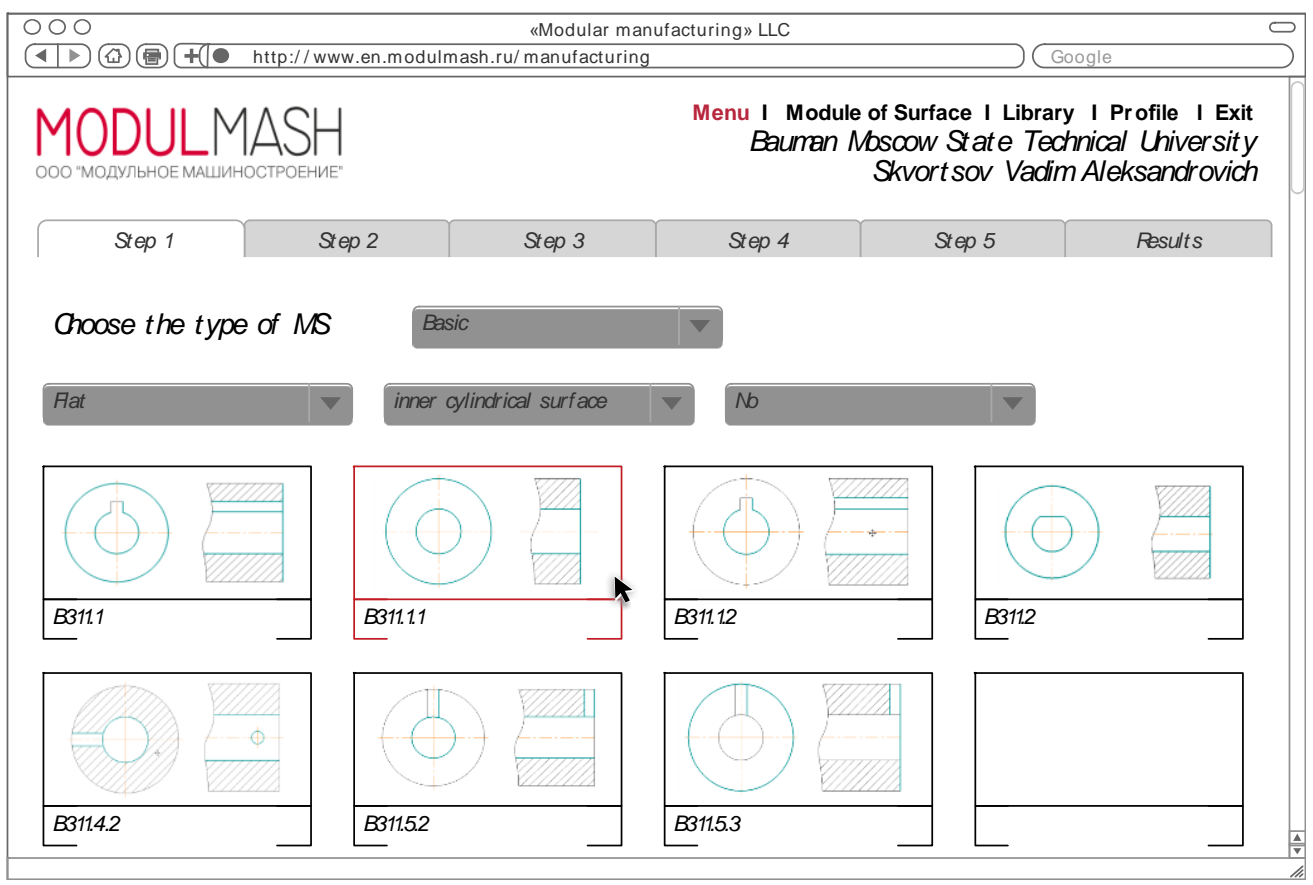

Figure 3. Interface of the expert system for choosing the surface module

When the technologist has entered the initial data for the surface module, the system carries out a search on the available options and offers various designs. The number of surface types in the basic modules can be from one to three. For example, let's take two surfaces. There are inner cylindrical and flat surfaces. For instance, let's consider the module B311.1.1. The modular technology means that a code is assigned to each surface module. Numbers are limited by points for easier perception. Figure 3 shows us the software interface where the user selects this surface module type. 
During the work with the knowledge base, the number of modules will increase. According to calculations, the approximate number of possible subtypes of the surface modules of each type of MS is about 8 million. Next, we ask user about dimensions, tolerances, and roughness for each surface. It is important to set the cutting conditions, tool selection, and surface treatment technology. Next step, we add the other necessary information, such as a volume of production, material of part and etc.

The expert system stores the information about the tools, machine tools, and other equipment. For this aim, we have already given information about the machine tools, its cost and the method of calculating depreciation.

\section{ADVANTAGES OF THE DEVELOPED CAPP SYSTEM}

The main advantage of the developed CAPP system is an automation of the decision-making during the technological process design. The modular approach allows to reduce the time required for search for technological solutions, decrease the complexity of technological process development by several times comparing to other existing technologies, and also improve a quality of technological preparation of production by using technological solutions that are tested practically. Thus, the "storage" for all technological solutions allowing to save and spread information in the enterprises is developed.

Another application of CAPP system is a work with suppliers of equipment - machines, tools, equipment (sales, advertising and promotion).

Designed expert system has the knowledge in the field of processing of each surface module, where each module corresponds to the several options surface processing modules. The reason for this is a large number of machining operations that can be used to produce a detail.

Another advantage of using the CAPP system is a training program that allows young technologists to gain the necessary knowledge and experience of previous generations of existing technologies, equipment, tools and processes that have ever been used.

\section{CONCLUSION}

The modular technology has appeared in the early 80s, and the theoretical principles of it still evolve. Despite the rather long existence of technology, the possibility of its application has appeared only in recent years since the software has reached a required level and allows integrating the CAPP system.

The aim of the designed expert system is to simplify the technologist work and hide the complex information system for the calculation of the internal algorithm. The interface of the developed CAPP system shows us the different combination of machine tools and other equipment like geometric characteristics of the cutting insert, the cutting insert material and recommended cutting conditions. Most of the information is enclosed in the knowledge database.

It was noticed, that we need to include a lot of input parameters to obtain more realistic characteristics. In some cases, we encountered inaccuracy of data in the directories. For instance, we noticed differences between the steel produced in Russia and other countries. They are characterized by the chemical composition which is specified in the regulations. Permissible limits of these elements differ in different countries. However, change of the limits within one percent can change the hardness of the material, and it will affect the tool life cycle. To solve this problem, it was proposed the solution to create the database with recommended, permissible and actual cutting conditions. Using the actual parameters of the cutting, we can gather information from the manufacturers.

At the first step we use simple details and only finishing machining operations. Our study serves as a window to an understanding of the process and the architecture of the CAPP system, design API and user interface of each component. "Feature Recognition Module of the CAPP System" article describes one of these components. In the following works, we are planning to conduct an experiment using an example of a complex case part. 


\section{REFERENCES}

Arzybaev A.M. et al, 2015. Methodology to determine applications for surface treatment method. Glavnyy mekhanik, No. 1, pp. 66-73.

Azarov, A. V. et al, 2019. Composite 3D printing for the small size unmanned aerial vehicle structure. Composites Part B: Engineering, Vol. 169, pp 157-163.

Bazrov B. M. et al, 2013. Quality of Surface Modules in Machine Parts. Russian Engineering Research, Vol. 33, No. 11, pp. 651-654.

Chao Liang et al, 2014. 3D Machining Process Planning Based On Machining Feature Recognition Technique. Advanced Materials Research, Vols. 945-949, pp 127-136.

Dezhina I.G. et al, 2015. Novye proizvodstvennye tekhnologii: publichnyy analiticheckiy doklad. Izdatel'skiy dom "Delo" RANKHiGS, Moscow, Russia.

Grabowik C. et al, 2014. A methodology of CAPP/CAP systems integration based on a product intermediate state representation, Advanced Materials Research. Vols. 1033-1036, pp 915-920.

Guowei Lan et al, 2014. Research on Aviation Aluminum Alloy Technology CAPP System Based on the Part Similarity, Applied Mechanics \& Materials, Vols. 536-537, pp 1447-1451.

Jong, Wen-Ren et al, 2015. Automatic process planning of mold components with integration of feature recognition and group technology, International Journal of Advanced Manufacturing Technology, Vol. 78, No. 5-8, pp 807-824.

Kafashi S. et al, 2012. Automated setup planning in CAPP: a modified particle swarm optimisation-based approach, International Journal of Production Research, Vol. 50, No. 15, pp 4127-4140.

Kondakov A.I. 2010. SAPR tehnologicheskih processov, Akademiya, Moscow, Russia.

Liyan Zhang, 2014. Machining feature-based CAD/CAPP for STEP-NC. Applied Mechanics \& Materials, No. 598, pp 591-594.

Meseguer A. et al, 2008. Methodology for cutting-tool management through the integration of CAPP and scheduling, International Journal of Production Research, Vol. 46, No. 6, pp 1685-1706.

Plokhikh, A. I. et al, 2019. Mechanical properties of multilayer materials. In IOP Conference Series: Materials Science and Engineering, Vol. 525, No. 1, p. 012045.

Sakharov, M. et al, 2019. Parallel Multi-memetic Global Optimization Algorithm for Optimal Control of Polyarylenephthalide's Thermally-Stimulated Luminescence. In World Congress on Global Optimization, Moscow, Russia, pp. 191-201.

Skvortsov, V. et al, 2019. Feature Recognition Module of the CAPP System. In 2019 IEEE Conference of Russian Young Researchers in Electrical and Electronic Engineering (EIConRus), Moscow, Russia, pp. 1769-1772.

Sunil, V. B. et al, 2009. Automatic recognition of machining features using artificial neural networks. International Journal of Advanced Manufacturing Technology, Vol. 41, No. 9-10, pp 932-947.

Vukolov, A. et al, 2019. 3D Application for Modeling of Involute Gear Manufacturing as the Assistance Solution for TMM Training. In IFToMM World Congress on Mechanism and Machine Science, Vol. 73, pp. 813-823.

Zhao, Hong Zhi et al, 2014. The Research of CAPP System Based on Knowledge Integration, Advanced Materials Research, Vol. 1048, No. 1 pp 571-574. 